\title{
The pathological anatomy of the nephrotic syndrome*
}

\author{
HANS U. ZOLLINGER \\ M.D. \\ Department of Pathology, University of Basle, Switzerland
}

THE morphological basis of the nephrotic syndrome has been intensively studied in hundreds of kidney centres. Recently, this research has clarified the morphology and most of the pathogenetic relations of the syndrome. On the other hand, as always occurs in research, new problems have arisen. Unfortunately it is still too early for the decisive step from explanation of this syndrome to successful therapy to be made, though there are signs that this final outcome of research work may be realized in the near future.

We can distinguish three periods in the development of our concept of the nephrotic syndrome. The first was shortly after the beginning of this century, when a primary tubular lesion was thought to be the cause of the syndrome. This is understandable, since the tubular changes, with the deposition of fat and doubly-refracting lipids combined with epithelial degeneration, dominate the histological picture. In a second period around the years 1920 until 1930, pre-renal disturbances of metabolism were thought to be the cause. Now, in the third period, we assume a disturbance of glomerular permeability to be the cause of the syndrome as well as of the tubular lesions.

There is still a certain discrepancy between clinical and pathological anatomical nomenclature. This difficulty could be eliminated if the clinician would talk exclusively of 'the nephrotic syndrome' and the morphologist of 'nephrosis'. These two terms are by no means identical. The clinician may observe the syndrome, for instance, in cases of ordinary hypertensive glomerulonephritis. On the other hand, pathological anatomy recognizes many non-inflammatory lesions of the glomeruli, the so-called glomerulonephroses, which lead only in very few cases to the nephrotic syndrome. In the following I shall only speak of those nephroses of the pathological anatomist, which are found in this syndrome. They are generally identical with the descriptive term 'lipoid nephrosis'.

\footnotetext{
* A special University of London Lecture in Pathology, delivered at the London School of Hygiene and Tropical Medicine, 5 March 1969.
}

\section{Lipoid nephrosis}

By lipoid nephrosis we mean an enlarged, yellow, pale kidney with a smooth surface. Histologically the most impressive change is the deposition of neutral fats and doubly-refracting lipids in groups of interstitial cells and mainly in the proximal convoluted tubules. Besides this change, there is a heavy accumulation of hyaline droplets in the tubules, a result of increased reabsorption of protein from the glomerular filtrate and its consequent accumulation in lysosomes. These hyaline droplets prove that there must be a glomerular disturbance of permeability for proteins. Interesting and important is the fact that the storage of lipids in early cases and in those with a focal distribution of damaged glomeruli may only affect those nephrons which belong to such damaged glomeruli. This fatty change, therefore, again seems to be the consequence of a disturbance of permeability of the glomeruli and not of a general disturbance of metabolism.

In most cases of lipoid nephrosis we find so-called interstitial foam cells, i.e. groups of single cells with a foam-like, swollen cytoplasm in alcoholtreated sections. Fat-staining proves that this foamlike structure is caused by storage of neutral fats and lipids. The nature of these cells has been debated for many years, since Löhlein (1905) looked upon them as lymphatic endothelial cells. Only recently investigations by Sanerkin (1963) and others (Rohr and Zollinger, 1969), proved their tubular nature. It has been shown that solitary foam cells first develop in the proximal convoluted tubules (Figs. 1 and 2), very rarely in distal tubules. When the neighbouring cells are involved they swell and finally the lumen disappears. We further observed that the basement membranes in such tubules become progressively thinner and finally disappear. The nuclei of foam-cells are mostly pycnotic. Some of these cells are shed and appear in the urine. Furthermore, by light and electron microscopy we could follow the fat droplets into the damaged basement membranes of the tubules and into the interstitial tissue. We, therefore, assume that the lipids pass the damaged glomeruli and are then reabsorbed by the 


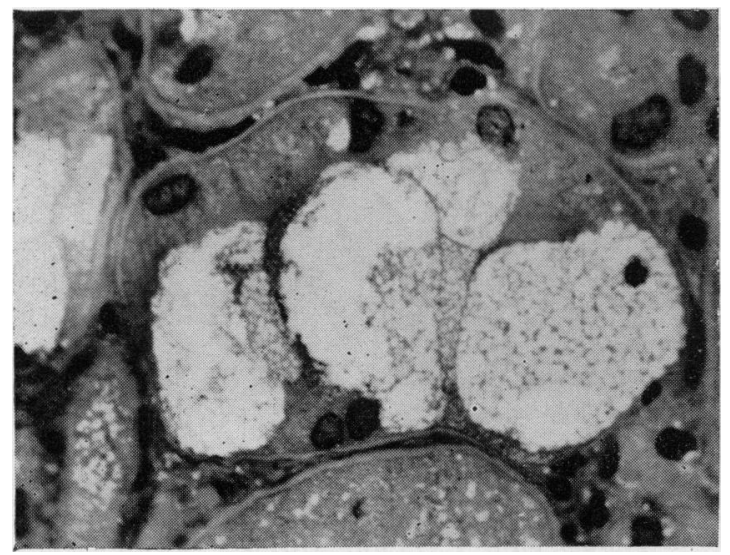

Fig. 1. Formation of foam-cells in a proximal convoluted tubule. Note the pycnotic nucleus in the cell on the right. Semi-thin, toluidine blue, $\times 800$.

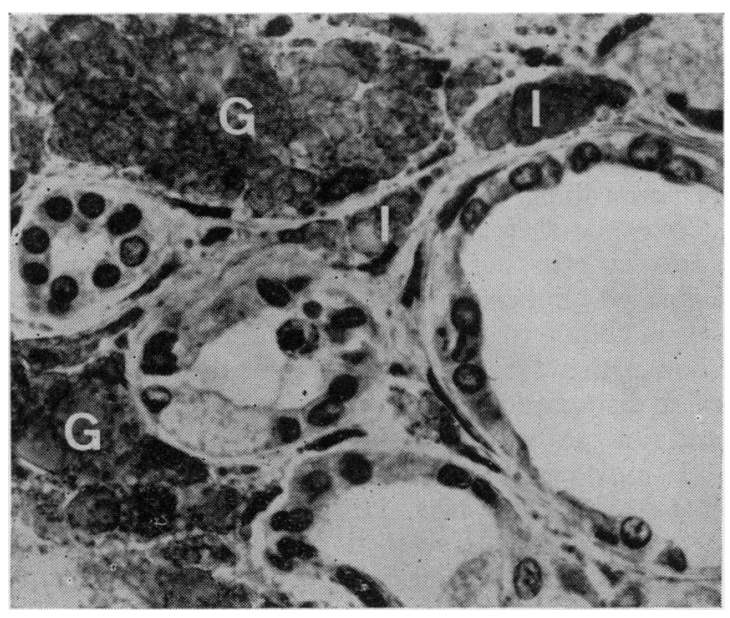

FIG. 2. $G=$ Group of foam-cells in infantile lipoid nephrosis. I $=$ Interstitial foam-cells. Sudan red, $\times 500$.

proximal convoluted tubules. So long as the lipids do not exceed the storage capacity of the cells they pass through the membranes to the interstitial tissues and finally to the peritubular capillaries. If the quantity is too great and/or the peritubular capillaries are obliterated, as we often observe by electron microscopy, foam-cells develop. On the whole there can be no doubt that foam-cell formation is an expression of cell degeneration. Glomeruular, mostly mesangial foam-cells are only exceptionally found in the nephrotic syndrome (see also McKenzie \& Kincaid-Smith, 1969).

Lipoid nephrosis may have various causes, but they are all related to lesions of the glomerula. Many other authors (Kark et al., 1958; Berman \& Schreiner, 1958, and others) have drawn attention to this wide pathogenic spectrum of the nephrotic syndrome. We can now distinguish at least five major groups of lesions: the still active inflammatory ones, minimal scar formation, infiltration by proteins, the toxic form and finally that caused by disturbances of the circulation.

\section{Active glomerulonephritis}

In this field great progress has been made through kidney biopsy which made electron microscopy applicable and by the technique of immunofluorescence. We shall not discuss the simple diffuse glomerulonephritis which produces hypertension besides the nephrotic syndrome. Much more complicated for the clinician is the problem of non-hypertensive forms of glomerulonephritis presenting with the syndrome.

A first type is called intracapillary glomerulonephritis, in which proliferation of the endothelial cells seems to be the cause of the enlargement of the glomerular stalk (Fig. 3), which leads to a typical lobular structure of the glomerular loops. Today we know that a proliferation of mesangial cells is the main change. The mesangial cells are the slowest reacting and by far the slowest regenerating glomerular element. Even weeks and months after clinical healing of acute glomerulonephritis, these elements may show still active lesions. The wellknown crescent formation may not develop if the attack of acute glomerulonephritis is mild. Then the inflammatory process is restricted to the loops and here particularly to the mesangium. There is no doubt that endothelial mitoses and other signs of endothelial proliferation occur. but they seem to disappear in a very short time (Kobayiashi \& Wada, 1961 ; Earle \& Jennings, 1967). Since the mesangium is situated inside the basement membrane of the capillaries, either the name 'intracapillary glomerulonephritis' or the purely descriptive term 'lobular glomerulonephritis' is correct.

The clinical history of such patients is rather typical: The 30-50-year-old patients usually do not recall an acute onset of the disease: it therefore falls into type II of Ellis (1942). The course is very chronic with a severe nephrotic syndrome. Hypertension is absent, except in some cases in the final stage. As the course is very chronic and the patients rather young, we believe that the onset of the disease often occurs in early childhood. At this stage, probably due to a relative weak antibody formation, acute glomerulonephritis produces less severe lesions in the glomeruli than in older patients. (We shall see later that in children mesangial reaction and regeneration occur more slowly than in older agegroups.) Furthermore, we never fail to observe the intracapillary component in a case of so-called extracapillary glomerulonephritis, i.e. with crescent formation. And finally, intra- and extracapillary 


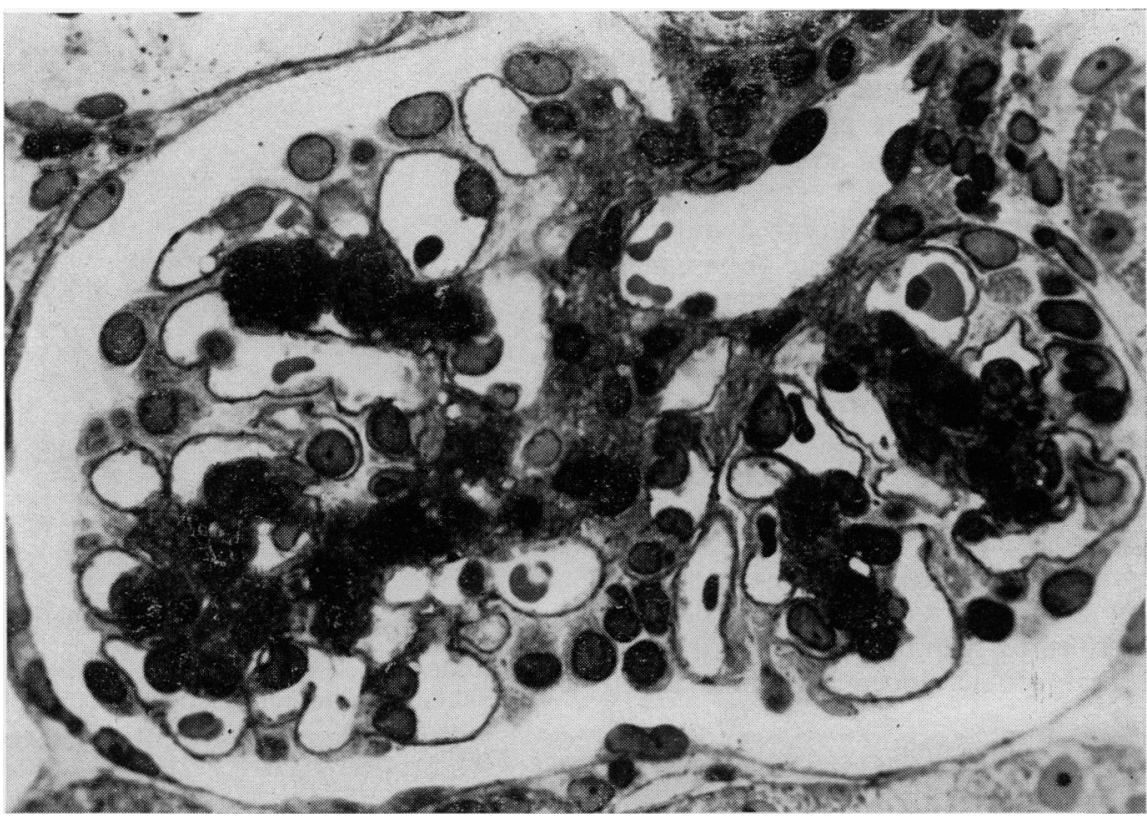

FIG. 3. Intracapillary subacute glomerulonephritis in a 7-month-old girl with a severe nephrotic syndrome. Enlargement of the mesangial space, increase in the number of nuclei. Periphery of the loops smooth. Azuremethylene blue, semi-thin, $\times 800$.

forms frequently co-exist. We therefore believe the two forms to have the same aetiology.

In silver or methylene-blue stained sections we can see a heavy deposit of membrane-like material in the mesangial intercellulary spaces (Fig. 3); later there is collagen-formation. Similar mesangial depositions are seen by electron microscopy (Fig. 4) and sometimes even nodular formations on the outside of the basement membrane can be found. Therefore circulating antigen-antibody complexes, which are thought to be the cause of acute post-streptococcal glomerulonephritis, are probably the provocative agents in intracapillary nephritis too. However, the search for aetiology should not overshadow the fact that the deposit mentioned above contains, besides immuno-complexes, fibrin, fibrinogen and fragments of these (Vasalli, Simon \& Rouillier, 1963; Simon \& Chatelanat, 1963; McCluskey et al., 1966).

Very problematic is the so-called membranous glomerulonephritis. It produces the nephrotic syndrome, usually without hypertension. On light microscopy the glomerular basement membrane is very thick. At first sight inflammatory reactions seem to be absent. But in all our necropsies, with many more glomeruli to evaluate, there could be found synechiae between loops and capsule and sometimes even larger glomerular scar formations. Mixed forms of membranous glomerulonephritis and simple glomerular nephritis are described by Royer, Habib \& Mathieu (1967) and others. In animal experiments,

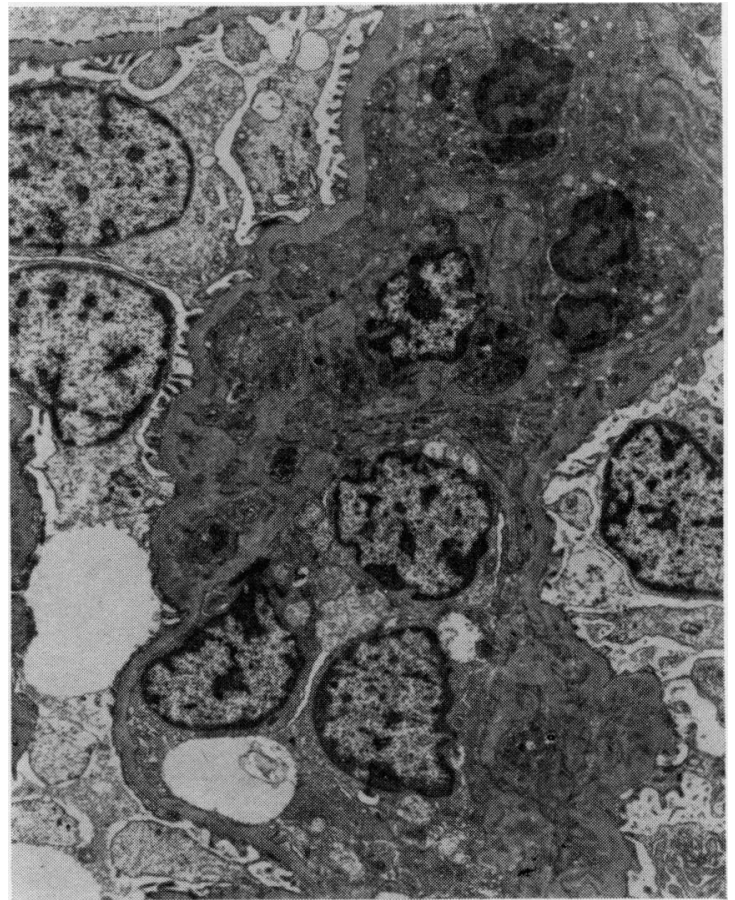

FIg. 4. Same case as Fig. 3. The enlarged mesangium contains dark depositions of basement-membrane-like material. Glutaraldehyde and osmium fix., uranyl stained. Electron microscopy, $\times 4500$. 
membranous glomerulonephritis can be produced by injecting antigen-antibody complexes (Germuth, Seutrerfit \& Pollak, 1967; Fennell \& Pardo, 1967). We may assume membranous glomerulonephritis to belong to the large group of streptococcal glomerulonephritides.

Special stains make visible plump nodular or radial depositions of so-called fibrinoid or basementlike material on the outside of the basement membrane, i.e. extra-membranous (Fig. 5). The electron microscope confirms these observations but reveals intra-membranous deposits as well (Fig. 6). This fibrinoid material is thought to represent antigenantibody complexes. There is still some discussion whether this complex formation is caused by a secondary disease, i.e. autoimmune disease, or whether it represents so-called 'humps' with delayed resorption. Nodular extra-membranous deposits have been described by Kimmelstiel (1965), in acute post-streptococcal glomerulonephritis and called

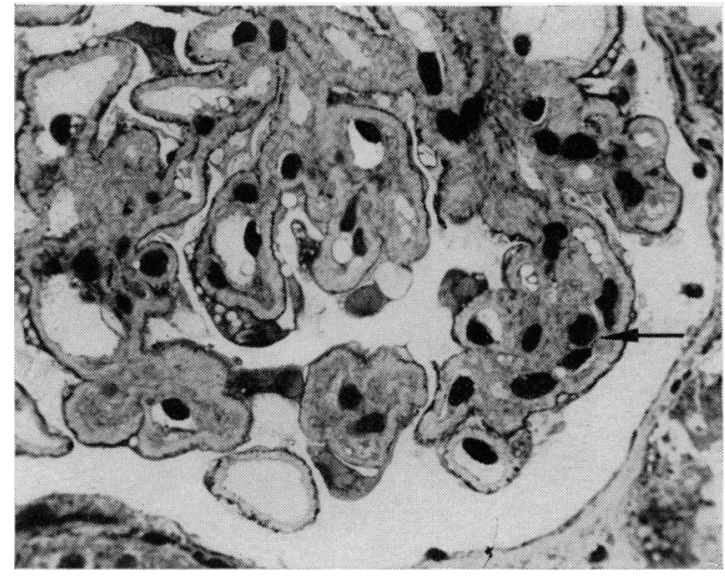

Fig. 5. Membranous glomerulonephritis. Basement membrane very thick with radial depositions on the outside. Some proliferation of mesangial cells (arrow). Semi-thin-section, toluidine blue, $\times 650$.

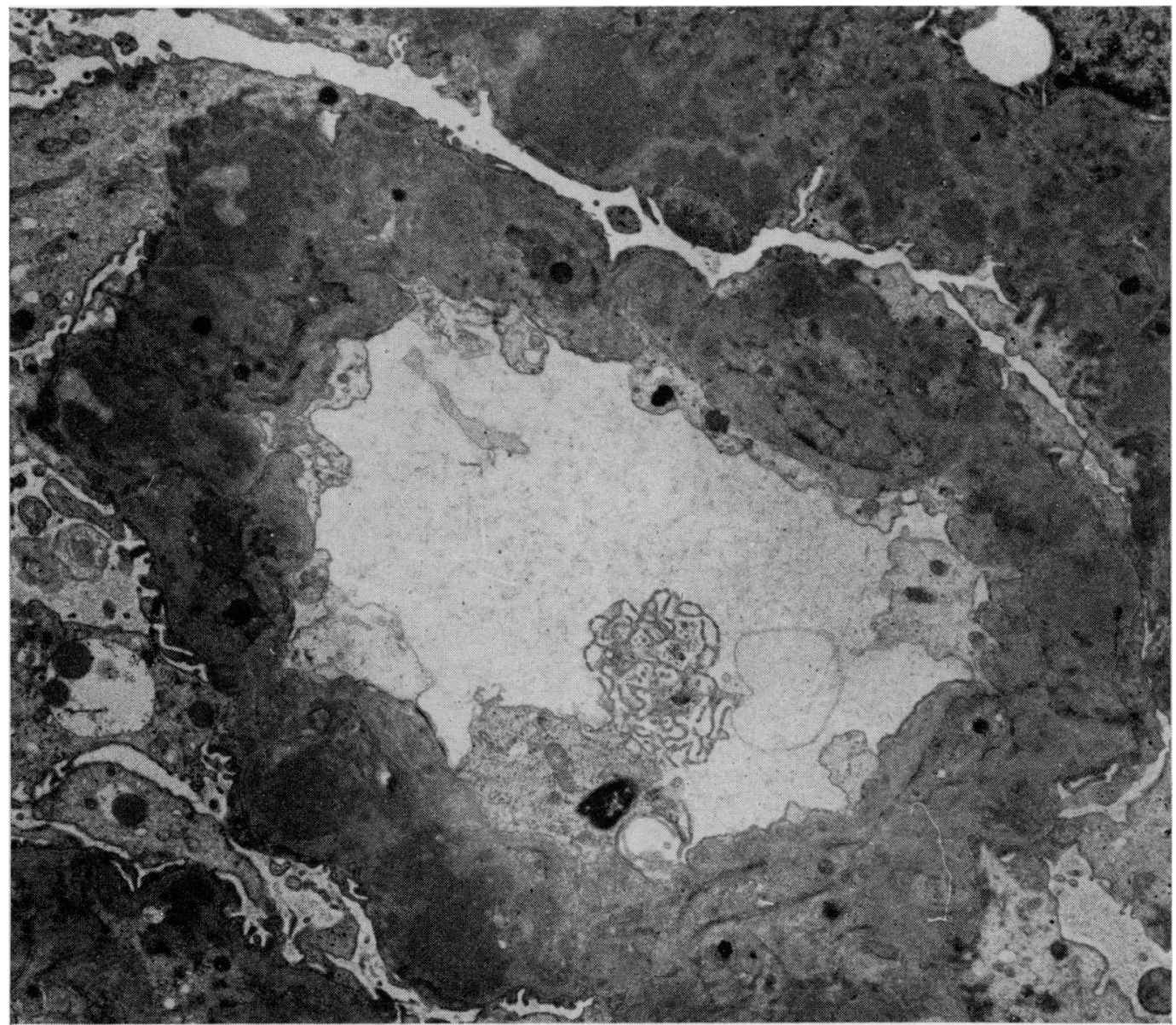

Fig. 6. Membranous glomerulonephritis seen by electron microscopy: heavy dark deposits, particularly on the outside, partially also on the inside of the basement membrane. Technique as for Fig. $4, \times 3500$. 
'humps' (Fig. 7). They consist of antigen-antibody complexes, streptococci probably being the antigen. They usually disappear in a few weeks and reappear in relapse. But in some cases they may remain visible for months (Vernier et al., 1967). Dixon (1966) and

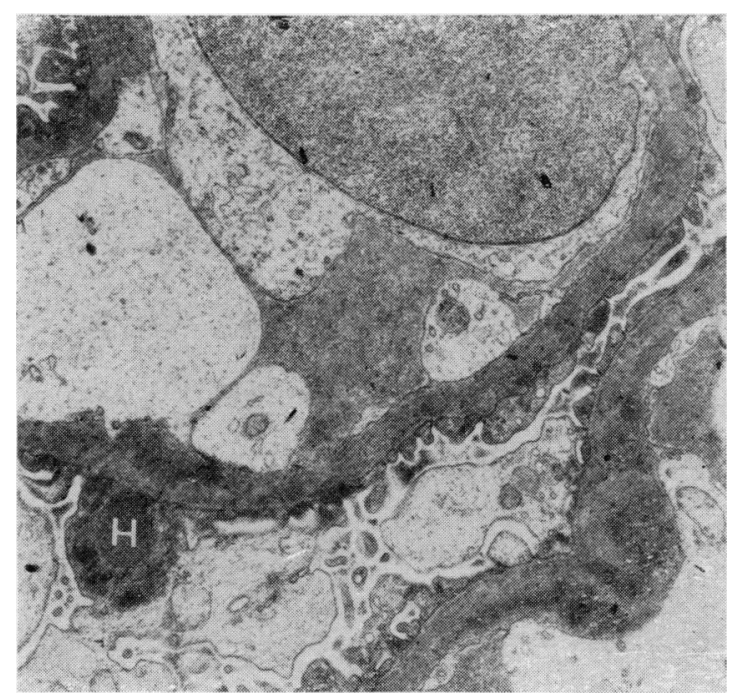

Fig. 7. 'Hump' on the outside of the glomerular membrane in a case of acute post-streptococcal glomerulonephritis. Technique as for Fig. 4, $\times 4500$.

his collaborators have shown that in the model of serum nephritis humps are caused by circulating antigen-antibody complexes which are filtered by the glomerular membrane, thereby forming deposits with positive nodular immunofluorescence on the outside of the basement membrane. In the second model of glomerulonephritis, i.e. nephrotoxic serum or Masugi nephritis the glomerular basement membrane represents the antigen while antibodies circulating in the blood are filtered. The deposits of complexes caused by this type are linear and on the inside of the membrane (endo-membranous). But we like to draw attention to the fact that membranelike deposits, if they are not real 'humps', are no proof of antigen-antibody processes. In our Institute, Moppert \& Fresen (1967) produced the formation of very large deposits in mice by daily injections of very high doses of ovalbumin, thereby inducing immuno-paralysis with consequent suppression of antibody formation and inflammatory reaction.

The course of membranous glomerulonephritis is very slow. The deposits have been thought to be irreversible in this case. Very recent investigations seem to prove that at least in some of these patients some resolution may take place. Unfortunately all our biopsy diagnoses were confirmed by necropsy!
It is not surprising that some types of focal glomerulonephritis such as lupus nephritis, glomerulitis in Wegener's syndrome and, very rarely, healed cases of subacute bacterial endocarditis may lead to the nephrotic syndrome, since all of them may produce a severe lesion of the glomerular filtering system. Whereas lupus nephritis is very probably caused by circulating immuno-complexes, nephritis in Goodpasture's syndrome is thought to be of the Masugi type, the glomerular basement membrane being the antigen.

Recently a large literature has accumulated on the subject of the nephrotic syndrome in the newborn, suckling babies and small children. Such kidneys usually show abundant small cystic formations (Fig. 8a). In the congenital form Kouvalainen (1962)

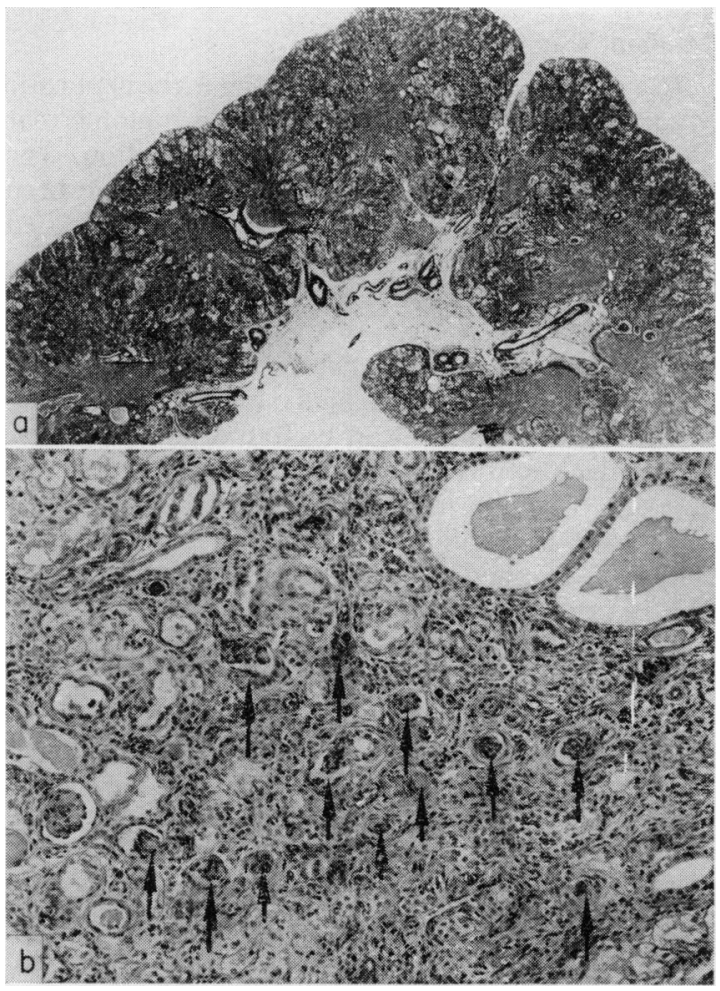

FIG. 8. (a) Microcyst formation in early infantile glomerulonephritis. Two-month-old girl with nephrotic syndrome. PAS, $\times 4$. (b) Higher magnification of (a). Tubular cyst formation and very small glomerular scars (arrows). H \& E, $\times 25$.

showed that transplants of infantile skin to the respective mothers were rejected much more quickly than normal, thereby proving that maternal antibodies against infantile tissues are present and probably produce the foetal glomerulonephritis. Habib (Habib et al., 1962) on the other hand 
believes this disease to be a malformation. She calls it 'oligonephronie' because she found a greatly reduced number of glomeruli. Contrary to this observation, in microscopic sections kindly placed at my disposal by Habib and in my own cases, we found a number of normal glomeruli, but many glomeruli were transformed to extremely small scars (Fig. 8b). We know that the glomeruli in infantile pyelonephritis shrink much more than in adult cases. Secondary tubular cyst formation may be seen in many cases of congenital or early post-natal nephritis. It represents an acquired lesion, as could be confirmed by producing pyelonephritis in newborn rabbits (Adler \& Zollinger, 1967). There seems to be no reason to exclude the congenital nephrotic syndrome from the glomerulonephritis group (Zollinger, 1969).

\section{Minimal scar formation}

In a second group of renal biopsies in the nephrotic syndrome particularly in children, glomerular changes cannot be found on first inspection. The term 'idiopathic lipoid nephrosis' has therefore been resuscitated. However, if very thin sections (called 'semi-thin' by the electron microscopist) are stained with PAS and looked at very carefully, small but definitely enlarged areas of the mesangium with an increased number of nuclei (Fig. 9a), containing PAS-positive and silver-stained basement membranelike material (Fig. 9b), can be found in most slides. Under the electron microscope the existence of these deposits is confirmed (Fig. 10). The basement membrane is focally thickened and the mesangial cells may or may not show increased activity (Fig. 11). In necropsy material with many more glomeruli we found this mesangial lesion in every case. It is focal and Fig. 12 shows how easily the biopsy needle may miss glomeruli exhibiting such lesions. Originally the mesangial scar-formation is probably caused by deposition of antigen-antibody complexes. Immunofluorescence is usually negative, but such complexes may disappear or chemically change, the lesion still progressing. In considering these mesangial changes as sequelae of a mild form of partially healed glomerulonephritis we have been supported by German and French authors in the last two congresses of Nephrology in Vienna and Strasbourg (see Zollinger \& Rohr, 1969).

This form of glomerular lesion had already been observed by other authors. They called it "latent glomerulonephritis' (Bell, 1946), 'defective healing' (Addis, 1948), 'latent phase' (Pirani \& Pollak, 1967), 'dormant glomerulonephritis' (Kimmelstiel, Osawa \& Beres, 1967), 'symptomatic glomerulonephritis' (Takatsu \& Sato, 1962) or 'focal sclerosing glomerulonephritis' (McGovern, 1967). We prefer the name 'minimal glomerular scar formation'.

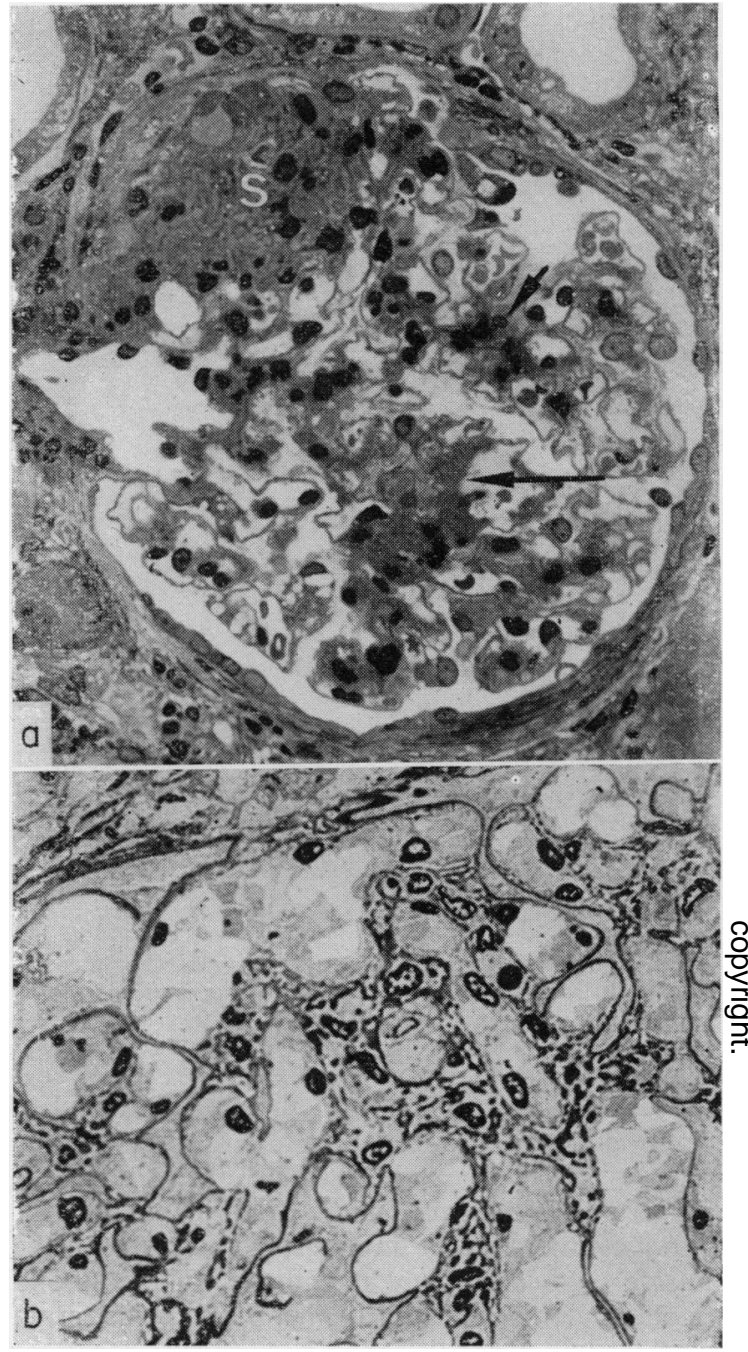

FIG. 9. (a) Minimal glomerular scar formation (arrows) indicating old inflammation. Large synechia (S). Sixteenyear-old boy, severe nephrotic syndrome without hypertension. Semi-thin, toluidine blue, $\times 600$. (b) Same case as (a). Silver stained: silver positive deposits in the mesangial space. Methenamin silver, $\times 800$.

These changes are the commonest cause of the nephrotic syndrome as has been stated recently by Cameron (1968), who confirms our opinion that they are mostly seen in children and young adults. We assume minimal glomerular scar formation to be a typical late result of infantile glomerulonephritis. The optimistic outlook of pediatricians in glomerulonephritis must therefore be reconsidered. Usually the case history is silent concerning the onset of the disease. Still, Bernstein et al. (1969), could detect periods of haematuria and/or hyper- 


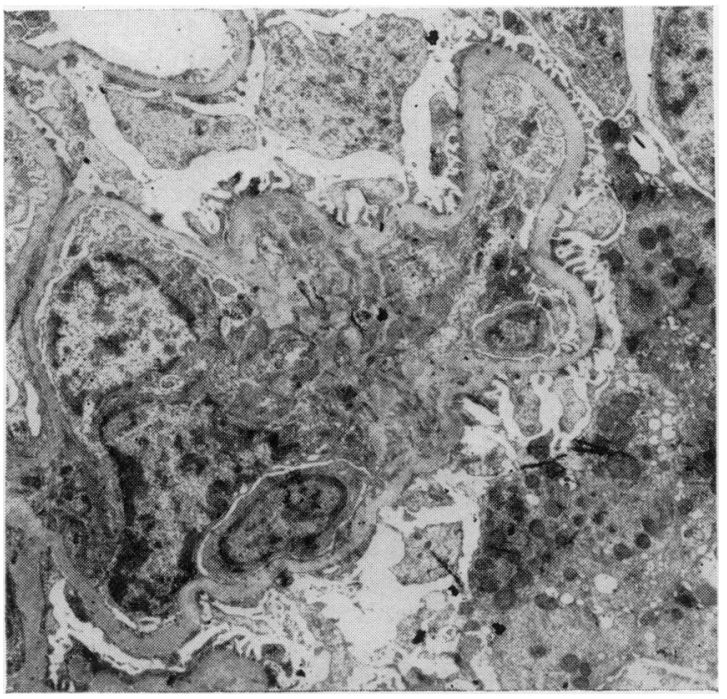

Fig. 10. Same case as Fig. 9 seen by electron micrcscopy: circumscript enlargement of the mesangial space; thickening and wrinkling of the basement-membrane, membrane-like-deposits in the mesangium. Same technique as for Fig. $4, \times 4500$.

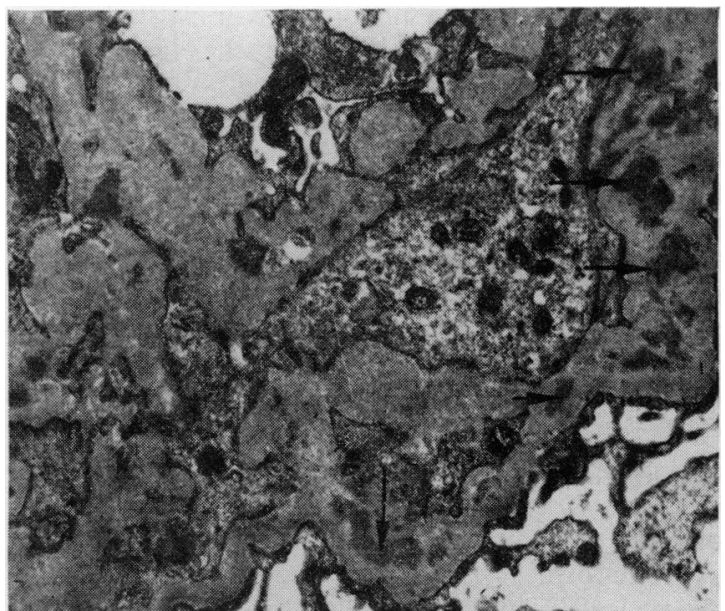

Fig. 11. Scar formation in the mesangial region. Sevenyear-old boy with nephrotic syndrome without hypertension. In the basement membrane are large depositions of dark material. The basement membrane is focally thickened. Technique as for Fig. 4, $\times 8000$.

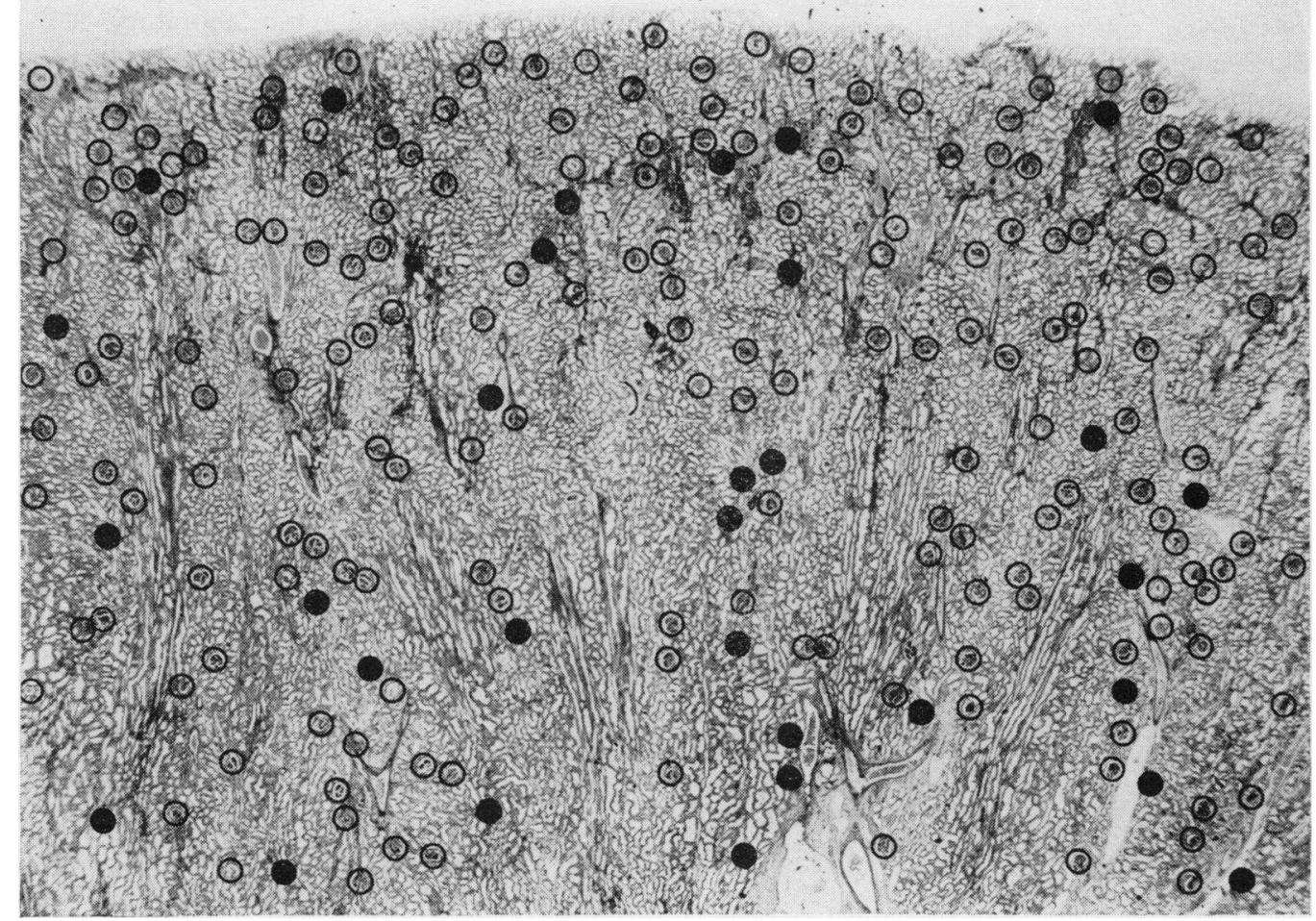

FIG. 12. Renal cortex of a 5-year-old girl with nephrotic syndrome. The black dots represent glomeruli with unquestionable scar formation, the empty rings indicate apparently normal glomeruli. PAS (reprinted from Z. Kinderheilk. 116, 1968). 
tension in their case histories. Kimmelstiel et al. (1967) found the onset, where the history was obtainable, to be in early childhood.

Some authors believe that such microscars are not the outcome of a post-streptococcal glomerulonephritis, but of a pathogenetically distinct focal glomerulonephritis. However, the occurence of focally distributed lesions in glomerulonephritis can not be taken as proof of focal glomerulonephritis. It is easy to produce a focal distribution of the glomerular inflammation in Masugi and in serum glomerulonephritis. In these cases only a few glomeruli are inflamed and in one glomerulus only part of the loops. The diagnosis of focal glomerulitis demands a relapsing course and/or specific lesions or reactions such as abscess formation, in the pyaemic form, haematoxylin bodies in lupus nephritis, typical inflammatory microthrombi in subacute bacterial endocarditis, etc. As these stigmata are lacking in minimal scar formations we consider it to be a typical outcome of infantile glomerulonephritis with relatively weak antibody formation.

\section{Infiltrations}

The third type of glomerular lesion causing the nephrotic syndrome called 'infiltrative' or 'dysorotic' shows no inflammatory reaction but heavy deposition of foreign substances such as amyloid or fibrinoid as in diabetic glomerulosclerosis. Secondary lipoid nephrosis even with foam-cell formation and the nephrotic syndrome are never absent in heavy amyloidosis of the kidneys. By 'dysorotic' we mean that the main disturbance is found in the boundary interfaces, particularly along the glomerular basement membrane. Amyloid is found between endothelium and basement membrane including the

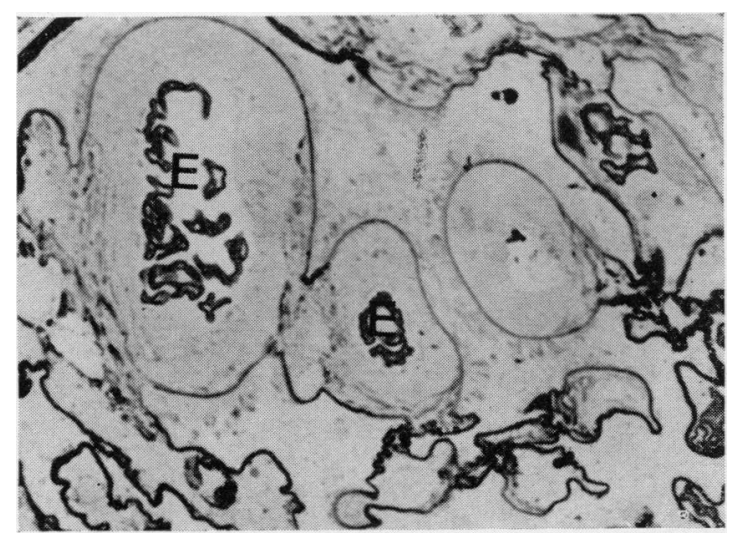

Fig. 13. Glomerulus with deposit of amyloid between the lumen (containing erythrocytes, E) and the basement membrane which is intact. Semi-thin, methenamin silver, $\times 800$. mesangial region (Figs. 13 and 14). The basement membrane itself remains optically and electronmicroscopically intact for a long time. Here I should like to point out that in minimal scar formation and in the lesions described later on, the membrane in the peripheral sectors of the glomerular loops remains intact too. Until now the actual reason for the proteinuria in these cases has not been explained. Scar formation, etc., are only the visible pointers.

\section{Toxic damage}

A fourth group of glomerular lesions called 'toxic' was found about 15 years ago when we were confronted with an increasing number of old patients with the nephrotic syndrome (Zollinger, 1955). All of them were long-standing cardiac cases, all of them had received heavy doses of mercurial diuretics with good effect until suddenly water retention and the nephrotic syndrome were observed. Macroscopically the kidneys were enlarged and showed very small bright yellow dots and radial stripes, and microscopy showed typical lipoid nephrosis. The glomerular mesangium was slightly widened, mesangial nuclear proliferation and other inflammatory sequelae were absent (Fig. 15). Thus the picture of a glomerulonephrosis was found. This ill-defined and only fragmentarily explained glomerular disease is now under intensive investigation in our laboratory.

The only common denominator in our cases was heavy mercurial therapy. Chemical analysis showed? high mercury contents of the kidneys, the highest being $250 \mathrm{mg} / \mathrm{kg}$ kidney. Similar cases have been seen in gunpowder factories (fulminate of mercury). The nephrotic syndrome disappears when the patient changes his place of work. Children furthermore showed an unexplained nephrotic syndrome, when calomel was still in use. Finally we succeeded in producing the syndrome in golden hamsters. In the literature a few cases of nephrotic syndrome caused by the exhibition of gold or bismuth are described.

\section{Circulatory disturbances}

The typical example of this group is lipoid nephrosis in chronic renal vein thrombosis. The nephrotic syndrome can be cured by nephrectomy if the thrombosis is unilateral. A similar picture may be caused by thrombosis of the inferior vena cava and by constrictive pericarditis. Experimentally a biochemically typical nephrotic syndrome can be produced by constriction of the renal vein (Mann, 1960; Fisher et al., 1968). The glomeruli in human and animal cases are very large and the loops are highly dilated. In human biopsies many authors described a remarkable thickening of the basement membrane by light as well as electron microscopy (Pollak et al., 1956; Humaire, 1962; Panner, 1963; Fisher et al., 1968). Furthermore the latter reveals 


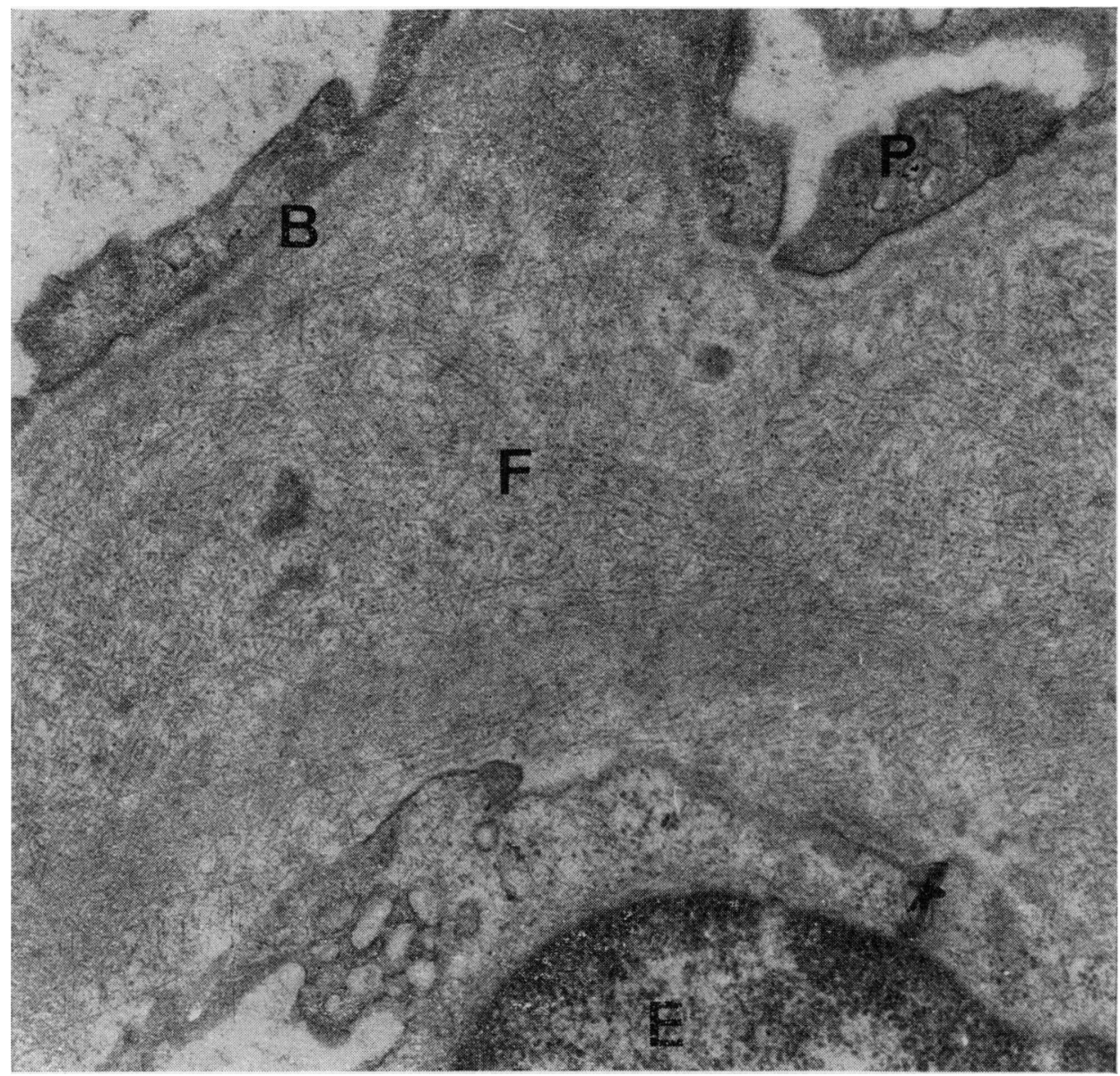

FIG. 14. Same as Fig. 13 seen by electron microscopy. $\mathbf{E}=$ Endothelial nucleus; $\mathbf{S}=$ fibrillary amyloid deposit; $\mathrm{B}=$ intact basement membrane; $\mathrm{P}=$ podocytes, foot processes. Technique as for Fig. $4, \times 18,000$.

large basement-membrane-like deposits on the outside of the membrane, containing $\gamma$-globulins (Sturgill \& Towe, 1967). Many authors, therefore, assume the glomerular changes in renal vein thrombosis to be of inflammatory origin. Still, in our necropsies we found a thickening of the basement membrane only once in a patient in whom a renal biopsy 6 months earlier had shown typical minimal scar formation (Fig. 16a and b). It is our opinion that this question merits reconsideration because in our animal experiments (Mann, 1960), membrane thickening was absent too. Renal vein thrombosis is known to be a typical complication of the nephrotic syndrome. With Fisher et al. (1968) we, therefore, suggest that at least in some cases of membrane thickening in renal vein thrombosis membranous glomerulonephritis or minimal scar formation were the primary process, thrombosis the consequence. At the last International Congress of Pathology in
Milan in 1968, a group of Dutch workers showed these deposits in renal vein thrombosis to be free of complement, thereby suggesting that insudation of plasma into the wall of the loops may produce thickened walls.

In this group also belongs orthostatic proteinuria. Hyperlordosis is thought to cause compression of the renal veins and proteinuria. However, King (1959) carefully followed such patients over years and showed one-third of them to present symptoms of glomerulonephritis. Therefore, it is possible that at least in some patients with occult minimal scar formation, hyperlordosis with renal vein strangulation only causes proteinuria to become manifest. $\mathrm{Be}$ it as it may, every case of orthostatic proteinuria should be investigated very thoroughly.

These are the five groups of glomerular lesions which up to now are known to cause heavy proteinuria and the nephrotic syndrome. This list will 


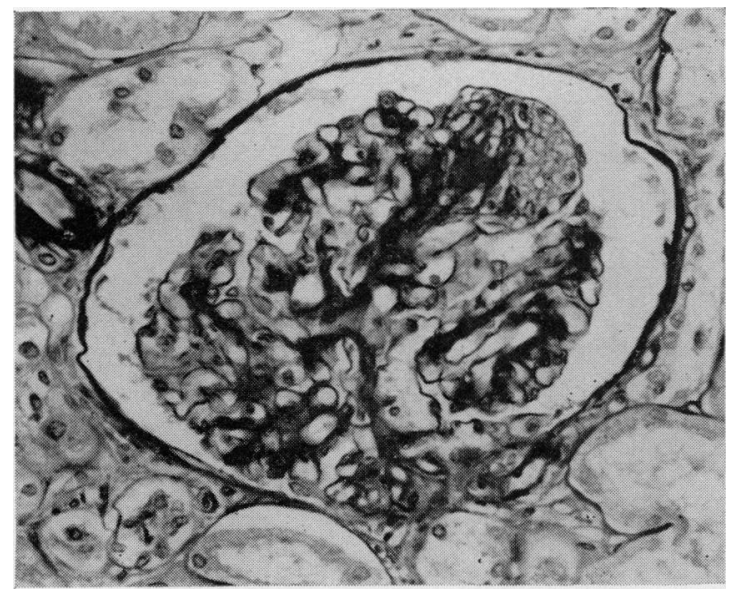

FIG. 15. Glomerulonephrosis after prolonged treatment with mercurial diuretics, $200 \mathrm{mg} \mathrm{Hg} / \mathrm{kg}$ kidney weight. Contrary to scar formation no increase of mesangial nuclei! 83-year-old man. PAS, $\times \mathbf{4 0 0}$.

certainly be enlarged in the future. It conclusively shows the syndrome to have many causes. Renal biopsy allows us to decide the nature of a particular case. The assumption that prophylaxis and therapy depend on this decision seems justified.

\section{Therapy}

It may seem presumptuous if a pathologist talks of therapy. Personally I am very much interested in therapy, it being at least partly the aim of our research. Generally speaking, most authors agree that the younger the patient with the nephrotic syndrome the better the results of steroid treatment. The best results occur with minimal scar formation as has been shown recently by Cameron (1968) (see also Drummond et al., 1966; Royer et al., 1967). Forms with acute proliferative and membranous glomerulonephritis on the other hand are thought to be steroid-resistant (Pirani \& Pollak, 1967; Ross, 1967, and others). Immunosuppressive therapy gives good results, if large deposits with positive immunofluorescence are present (Michael, 1967; Dixon, 1967) and at least may improve those with active proliferation (Vernier et al., 1967).

\section{Pathogenesis of symptoms}

I shall not try to explain at length the pathogenesis of the various symptoms of the syndrome. Proteinuria and its results, hypoproteinaemia and cylindruria, are sufficiently explained by glomerular lesions of the type described above. Unexplained are the hypercholesterolaemia and lipidaemia. Many authors assume the loss of albumin to evoke an increased production of albumin and $\beta$-globulin, i.e. lipoproteins by the liver. On the other hand it cannot be denied that the kidney is one of those

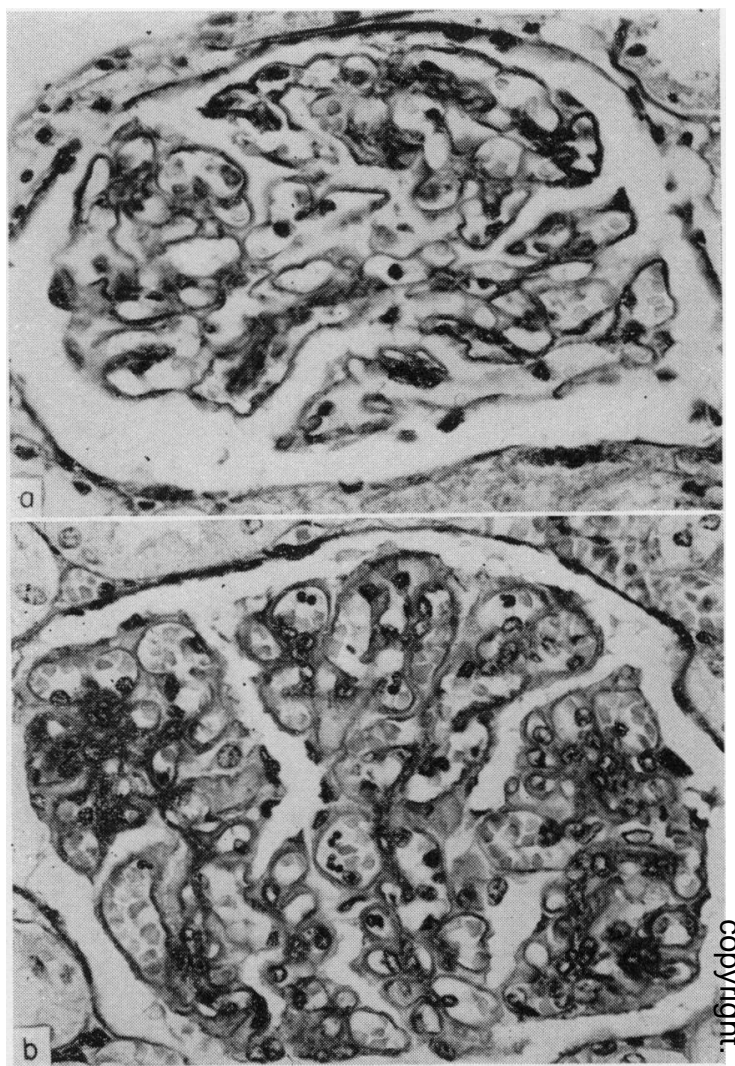

Fig. 16. (a) Kidney-biopsy: mesangial minimal scarformation in a 42-year-old man with nephrotic syndrome. PAS, $\times 100$. (b) Same case as (a), 6 months later. Necropsy: renal vein thrombosis: dilatation of glomerular loops, slight enlargement of mesangial space. No membranous changes! PAS, $\times 400$.

organs which play an important role in lipid metabolism. Reubi \& Schmid (1955) showed the kidney in lipoid nephrosis to produce increased amounts of non-metabolizable lipids (see Lagrue et al., 1964). Besides many earlier experimental findings the results of Sneider \& Shore (1968) point in this direction: isolated dog kidneys are able to incorporate inorganic phosphorus-32 into phospholipids; they reabsorb phospholipids from the perfusion fluid and secrete phospholipids into it. The kidney of the dog is therefore able to synthesize phospholipids. Finally it has been shown by Cantin (1965) that total nephrectomy or ligature of both ureters leads to an increase in total lipids, in cholesterol and in phospholipids in the blood, even if uraemia is absent. Whether hyperlipidaemia in the syndrome is exclusively of renal origin as suggested by Heymann \& Clark (1945) seems questionable.

Concerning oedema the pathologist has nothing to offer. He can neither demonstrate generalized 
capillary lesions nor regularly find adrenal changes which would support the hypothesis of hyperaldosteronism. Hypoproteinaemia still seems to be the best explanation for the oedema formation.

Finally we tried to find common denominators among the various organs in the syndrome. Unfortunately we could not find any. Two decades ago more than $70 \%$ of the patients died of infections, mostly peritonitis, whereas now the patients live much longer and die of uraemia or cardiac failure.

The pathogenetic mosaic of the nephrotic syndrome seems to be generally speaking complete, as far as morphology is concerned. In the next phase, the small details have to be worked out. We particularly need a reliable classification of the ultrastructural glomerular lesions including the results of immunofluorescence. We are just now in the middle of this process of analysis. There is no reason for the clinician to doubt the final importance of the seemingly ridiculous 'butterfly-collection' of the nephrologist. If we hope that synthesis will follow soon, we know that undoubtedly a very close co-operation with the clinician and many serial biopsies will be indispensable in achieving this result.

\section{Acknowledgment}

I am indebted to Dr Hans-Peter Rohr for the electron micrographs.

\section{References}

AdDis, T. (1948) Glomerular Nephritis. Diagnosis and Treatment. Macmillan, New York.

AdLER, C.P. \& Zollinger, H.U. (1967) Differenzierungsstörungen (sekundäre Missbildungen) bei der prae- und postnatalen Pyelonephritis von Mensch und Kaninchen. Frankf. Z. Path. 76, 127.

Bell, E.T. (1964) Renal Diseases. Lea \& Febiger, Philadelphia.

Berman, L.B. \& Schreiner, G.E. (1958) Clinical and histological spectrum of the nephrotic syndrome. Amer. J. Med. 24, 249.

Bernstein, J., Spitzer, A., Moore, E.S., Edelmann, C.M., $J_{R}$ \& White, R.H.R. (1969) Pathologic significance of a 'nephritic' onset in childhood nephrotic syndrome. Amer. J. Path. (In press).

CAMERoN, J.S. (1968) Histology, protein clearances, and response to treatment in the nephrotic syndrome. Brit. med. J. 2, 352.

CANTIN, M. (1965) Kidney, parathyroid, and lipemia. Lab. Invest. 14, 1891.

Dixon, F.J. (1967) The pathogenesis of immunologically induced nephritis. Proc. 3rd Int. Congr. Nephrol., Washington 1966, Volume 2, p. 97. Karger, Basel.

Drummond, K.N., Michael, A.F., Good, R.A. \& Vernier, R.L. (1966) The nephrotic syndrome of childhood: immunologic, clinical and pathologic correlations. J. clin. Invest. 45, 620.

EARLE, D.P. \& Jennings, R.B. (1967) Glomerulonephritis. Proc. 3rd Int. Congr. Nephrol., Washington 1966, Volume 3, p. 51. Karger, Basel.

Ellis, A. (1942) Natural history of Bright's disease. Lancet, i, 1 .
Fennell, R.H., JR \& PARdo, V.M. (1967) Experimental glomerulonephritis in rats. Lab. Invest. 17, 481.

Fisher, E.R., Sharley, D., Pardo, V.M. \& Vuzewski, V. (1968) Experimental renal vein constriction. Lab. Invest. $18,689$.

Germuth, F.G., Seutrerfit, L.B. \& Pollak, A.D. (1967) Immune complex disease. I. Experimental acute and chronic glomerulonephritis. Johns Hopkins med. J. 120, 225.

Habib, R., Courtecuisse, V., Mathieu, H. \& Royer, P. (1962) Un type anatomo-clinique particulier d'insuffisance rénale chronique de l'enfant: l'hypoplasie olionéphronique congénitale bilatérale. J. Urol. Néphrol. 68, 139.

HeymanN, W. \& Clark, E.C. (1945) Pathogenesis of nephrotic hyperlipemia. Amer. J. dis. Child. 70, 74.

Humair, L. (1962) Thromboses des veines rénales. Ann. Anat. Path. 7, 5.

Kark, R.M., Pirani, C.L., Pollak, V.E., Muehrcke, R.C \& BLAINEY, J.D. (1958) The nephrotic syndrome in adults: a common disorder with many causes. Ann. intern. Med. 49, 751.

Kimmelstiel, P. (1965) The hump: a lesion of acute glomerulonephritis. Bull. Path. Amer. Soc. clin. Path. 6, 187.

Kimmelstiel, P., Osawa, G. \& Beres, J. (1967) Some glomerular changes by electron microscopy with predominant mesangial reaction. Proc. 3rd Int. Congr. Nephrol., Washington 1966, Volume 2, p. 17. Karger, Basel.

KING, S.E. (1959) Albuminuria (proteinuria) in renal diseases. II. Preliminary observations on the clinical course of patients with orthostatic albuminuria. N.Y. State J. Med. $59,825$.

Kobayashi, O. \& Wada, H. (1961) Renal biopsy studies of early stages of acute glomerulonephritis in children. Acta med. Biol. (Niigata), 9, 75.

Kouvalainen, K. (1962) Immunological studies on congenital nephrosis. Amer. J. dis. Child. 104, 554.

Lagrue, G., Bariety, Z., Morard, J., Halpern, B.N., Milliez, P. (1964) Les syndromes néphrotiques expérimentaux: déductions pathogéniques. Path. Biol. 12, 735.

LöHLEIN, M. (1905) Ueber Fettinfiltration und fettige Degeneration der Niere des Menschen. Virchows Arch. path. Anat. 180, 1.

MANN, M. (1960) Morphologische Spätveränderungen und nephrotisches Syndrom nach einseitiger Nierenvenendrosselung bei der Ratte. Z. ges. exp. Med. 133, 270.

McCluskey, R.T., Vassalli, P., Gallo, G. \& Baldwin, D.S. (1966) An immunofluorescent study of pathogenetic mechanisms in glomerular disease. New Engl. J. Med. 274, 695 .

MCGovern, V.J. (1967) Glomerulonephritis. Pathology Annual (Ed. by S.C. Sommeis), Volume 2, p. 1. Butterworth, London.

McKenzie, I.F. \& KinCaid-Smith, P. (1969) Foam cells in the renal glomerulus. J. Path. 97, 151.

Michael, A. (1967) Immunosuppressive therapy of glomerulonephritis. Acute Glomerulonephritis (Ed. by J. Metcoff), p. 391. Churchill, London.

MOPPERT, J. \& Fresen, K.O. (1967) Experimentelle Glomerulonephritis und Glomerulonephrose bei der Maus nach wiederholten Ovalbumininjektionen. Virchow's Arch. path. Anat. 342, 304.

PANNER, B. (1963) Nephrotic syndrome in renal vein thrombosis. Arch. Path. 76, 303.

Pirani, C.L. \& Pollak, V.E. (1967) Longitudinal studies of renal biopsies. Proc. 3rd Int. Congr. Nephrol., Washington 1966, Volume 2, p. 212. Karger, Basel.

Pollak, V.E., Kark, R.M., Pirani, C.L., Shafter, H.A. \& MuehrCKe, R.C. (1956) Renal vein thrombosis and the nephrotic syndrome. Amer. J. Med. 21, 496. 
Reubi, F. \& Schmid, A. (1955) L'hyperlipidémie du syndrome néphrotique est-elle d'origine rénale? Z. Urol. méd. Chir. 5, 304.

RoHR, H.P. \& Zollinger, H.U. (1969) Struktur und Bedeutung der renalen Schaumzellen. Virchows Arch. path. Anat. (In press).

Ross, E.J. (1967) Effect of long-term steroid therapy in adults. Proc. 3rd Int. Congr. Nephrol., Washington 1966, Volume 3, p. 108. Karger, Basel.

Royer, P., Habib, R. \& Mathieu, H. (1967) Nephrologie im Kindesalter. Thieme, Stuttgart.

SANERKIN, N.G. (1963) On the nature of 'interstitial foam cells' in chronic glomerulonephritis. J. Path. Bact. 86, 135.

Simon, G. \& Chatelanat, F. (1963) Fibrin et fibrinoid dans les glomérulopathies. Etude comparée en pathologie expérimentale et spontanée. Path. microbiol. 26, 191.

SNeIDER, T.W. \& SHORE, M.L. (1968) Synthesis and utilization of plasma phospholipid by the isolated perfused dog kidney. Lab. Invest. 19, 181.

Sturgill, B.C. \& Towe, C.T. (1967) Renal vein thrombosis and the nephrotic syndrome. Immunofluorescence studies. Arch. intern. Med. 120, 708.
TAKatsu, T. \& Sato, H. (1962) On the specificity of the manifestation of chronic glomerulonephritis in children. Ann. paediat. 199, 366.

Vassalli, P., Simon, G. \& Rouillier, Ch. (1963) Electron microscopic study of glomerular lesions resulting from intravascular fibrin formation. Amer. J. Path. 43, 306.

Vernier, R.L., Finglof, B., Urizar, R., Litman, N. \& SMITH, F. JR (1967) Immunofluorescence studies in renal disease. Proc. 3rd Int. Congr. Nephrol., Washington 1966, Volume 3, p. 83. Karger, Basel.

ZOLLINGER, H.U. (1966) Niere und ableitende Harnwege. Hdb. Spez. Path.-Anat. (Ed. by W. Doerr \& E. Uehlinger). Springer, Berlin. (General list).

ZoLliNGER, H.U. (1955) Autoptische und experimentelle Untersuchungen über Lipoidnephrose, hervorgerufen durch chronische Quecksilbervergiftung. Schweiz. Z. Path. $18,155$.

Zollinger, H.U. (1969) Die pathologische Anatomie glomerulärer Erkrankungen im Kindesalter. Monatsschr. Kinderheilk. 117, 311.

ZOLLINGER, H.U. \& RoHR, H.P. (1969) Glomeruläre Narben und nephrotisches Syndrom. VI Symp. Gesellsch. Nephrologie, p. 429. Wien. Akad. Med. Fortbildung. 